\title{
Water Conservation Through Voluntary Responsible Behaviour at Botho University in Botswana
}

\author{
Shantha Indrajith Hikkaduwa Liyanage ${ }^{1}$, Venkataraman Vishwanathan ${ }^{2}$ \\ ${ }^{1}$ Faculty of Business and Accountancy, Botho University, Gaborone, Botswana \\ ${ }^{2}$ Faculty of Engineering \& Applied Sciences, Botho University, Gaborone, Botswana
}

Email address:

shantha.indrajith@bothouniversity.ac.bw (S. I. H. Liyanage), venkataraman.vishwanathan@bothouniversity.ac.bw(V.Vishwanathan)

To cite this article:

Shantha Indrajith Hikkaduwa Liyanage, Venkataraman Vishwanathan. Water Conservation through Voluntary Responsible Behaviour at Botho University in Botswana. American Journal of Applied Psychology. Vol. 9, No. 2, 2020, pp. 34-41. doi: 10.11648/j.ajap.20200902.11

Received: March 5, 2020; Accepted: March 23, 2020; Published: April 7, 2020

\begin{abstract}
In 2016, the Paris agreement on climate change agreed to limit the global warming well below $2^{\circ} \mathrm{C}$, and ideally $1.5^{\circ} \mathrm{C}$ by the end of the century. Even-though the global temperature on track shows a raise towards $3.2^{\circ} \mathrm{C}$ by the end of the century breaking $1.5^{\circ} \mathrm{C}$ target by 2040 , one wonders how the Adaptation at Scale in Semi-Arid Regions (ASSAR) assessed the vulnerability of Botswana in reaching the limit, $2^{\circ} \mathrm{C}$. Accordingly, Botswana will show a steady raise in temperature to $2.8^{\circ} \mathrm{C}$, the annual rainfall will drop by $9 \%$ and increase in dry days by 17 extra days. In addition, even the Limpopo catchment in Botswana will show a decline by $36 \%$. Given these scenarios, water as a lifelong commodity becomes highly vulnerable in Botswana. With a view to mitigate the intensity, the local, regional and international legal, policy and institutional framework legislated, agreed otherwise ratified expects a sustainable water management by voluntary, responsible behaviour from the consumers apart from other stakeholders in Botswana. For example, 2030 Agenda for 17 SDGs: the SDG 06: Clean Water and Sanitation \& $12^{\text {th }}$ SDG: Responsible Consumption and Production. Consequently, this study qualitatively investigated the exante and ex-post behavior of a consumer manifested by the strategic management in the light of theory of planned behavior for the water conservation project implemented by installation of newer water efficient appliances at Botho University in a landlocked country, Botswana. The test of theory of planned behaviour finds that the attitudes, social norms and Perceived Behavioural Control of the strategic management made strong intention for the responsible behavioural change in implementing the project. Further, the project has been able to save the water by $80 \%$, supply water continuously to consumers, protect the environment and further a cost saving to the university. These findings will be significant to ascertain how antecedent factors determine the decision making behaviour of a water conservation project. Such understanding acts as a catalyst for African universities to be a beacon of vision and mission in water conservation, distribution and governance in Africa in which continent $33 \%$ of people are affected by water scarcity which is getting worse with urbanization, population, industrial use and climate change.
\end{abstract}

Keywords: Global Warming, SDGs, Water Conservation, Theory of Planned Behaviour, Voluntary Behaviour

\section{Introduction}

Botswana is a semi-arid country which has got characteristics such as unreliable rain, low rain fall, constant drought and high rate of evaporation. These characteristics of semi-arid country, Botswana, contributes for water scarcity creating a water stress country with limited water resources. These limited water resources of Botswana are of two types. The primary source is the surface water from rivers, pans and dams. All these perennial rivers flow from neighbouring countries. The other source is limited underground water from aquifers some of which are fossil nature without recharge. These water resources are increasingly inadequate for current demand. Department of Water Affairs- Ministry of Minerals, Energy \& Water Resources reports in their IWRM-WE that "Water resources are increasingly scarce; the opportunities of additional water infrastructure are limited and the cost is very high. The estimated combined sustainable yield of Botswana's well fields and storage dam is $165 \mathrm{Mm}^{3} /$ annum or $216 \mathrm{~L} /$ person/day, based on the 2011 national population census estimate of 2024904 people. This is less than the current demand of around $200 \mathrm{Mm}^{3} /$ per 
annum or $262 \mathrm{~L} /$ person/day" [6].

In addition, the climate change induced by Global warming created and creating by anthropogenic activities of people around the world such as burning of fossil fuel, cement production etc. for example, deposit of 40 billion of tons of $\mathrm{CO}_{2}$ in the atmosphere per annum [9] makes the country like Botswana more vulnerable. A small change in global temperature results in serious local consequences. In 2016, the Paris agreement on climate change agreed to limit the global warming well below $2^{\circ} \mathrm{C}$, and ideally $1.5^{\circ} \mathrm{C}$, by the end of the century. Even-though the global temperature on track shows a raise towards $3.2^{\circ} \mathrm{C}$ by the end of the century breaking $1.5^{\circ} \mathrm{C}$ target by 2040 , one wonders how the Adaptation at Scale in Semi-Arid Regions (ASSAR) assessed the vulnerability of Botswana in reaching the limit, $2^{\circ} \mathrm{C}$. Accordingly, Botswana will show a steady raise in temperature to $2.8^{\circ} \mathrm{C}$ instead of $2^{\circ} \mathrm{C}$, the annual rainfall will drop by $9 \%$ and dry days will increase by 17 extra days. In addition, the Limpopo catchment in Botswana will show a decline by $36 \%$. Given these scenarios, water as a lifelong commodity becomes highly vulnerable in Botswana [5].

In order to meet the challenges of increasing scarcity of water created naturally and man-made global warming, Botswana has placed national, regional and international legal, policy \& institutional framework. The framework includes Botswana National Water Policy, Botswana Integrated Water Resources Management \& Water Efficiency Plan, Water Utilities Corporation Act of 1970, SADC Protocol on Shared Watercourses [6], 2016 Paris Agreement for limiting global warming and 2030 Agenda for Sustainable Development Goals. In all these legal and policy framework, one of the main objective and a strategy intended by them is the conservation of water by all users in a country.

In aligning with local, regional and international voice for voluntary behaviour for water conservation, the strategic plan of the university under this study entitles as Sustainable Growth Strategy 2018-2022 provides specifically first time inter alia that "Environmental sustainability is also critical to ensuring that the world as we know it exists; environmental degradation symptomatically felt through higher temperatures, water shortages, harsh weather and food shortages affect the growth of any organisation and its community. Sustainability alludes to a sense of responsibility that any large organization like Botho University has for its people, society and the environment".

Accordingly, as a sense of voluntary behavioural responsibility, the strategic management of Botho university under this study launched a water conservation project at one of the campuses in Botswana giving priority before two more projects in the progress of feasibility stage, solar photo voltaic system for generation of clean energy and efficient use of fossil fuel burning electricity used by the university.

The "Dublin Principles" of Water and Sustainable Development identifies water as a finite vulnerable resource with an economic value and therefore water should be considered as an economic goods. In agreeing with the "Dublin Principle", the water policy of Botswana provides that the cost of the water to the user should ensure that the water is wisely used in supporting the development and application of technology for improving efficiency [12]. Regional and international policy framework are also aligned with the framework above mentioned. The SDG 06: Clean Water and Sanitation \& SDG 12: Responsible Consumption and Production encourage industries, businesses and consumers in Botswana to reduce water footprint by responsible consumption of water. The common thread woven across all these frameworks, local, regional and international, is the demand management of water by voluntary behaviour of stakeholders, specially, the consumers.

In these circumstances, the research problem in this study is to ascertain the psychological factors which determine the voluntary behaviour of the university as a consumer. Hence, a curiosity arises how the behaviour of consumer, the university under this study, is demonstrated psychologically in decision making by the strategic management and implementation of the water conservation project with water efficient appliances at the main campus of the university which has been able to reduce the water footprint and provides benefits at micro level to the university and macro level to the society at large.

Consequently, this socio-psychological research investigates four socio-psychological factors of theory of planned behavior, namely, behavioral beliefs, normative beliefs, control beliefs as three antecedents which produces the intention to act. The novelty of this applied research is that the investigation is carried out on interpretivist approach due to the nature of data available whereas the theory of planned behavior was originally designed and abundantly tested under positivist approach. As a result, the limitation of the study is that causal relationship is not statistically representative. However, the findings of the study will be significant to ascertain qualitative causal relationship how antecedent factors determine the decision making behaviour of consumers for the water conservation project. Such understanding acts as a catalyst for African universities to be a beacon of vision and mission in water conservation, distribution and governance in Africa in which continent $33 \%$ of people are affected by water scarcity which is getting worse with urbanization, population and industrial use.

\section{Literature Review}

The strategic decision and the action of the University for implementing the water conservation project reflect the water conservation behaviour of the university which is analysed based on the theoretical framework consisting of Theory of Reasoned Action (TRA) and Theory of Planned Behaviour (TPB). The theoretical framework guides the research to explain the cognitive processes of strategic management for the water conservation project together with the outcome of the project.

The theory of reasoned action developed by Ajzen and Fisherin [1,2] explain the relationship between the attitude 
and behaviour which relationship is referred to as the A-B relationship. They argue that the actual behaviour is an outcome of the intention to perform a certain behaviour. The intention to perform the behaviour is determined by the preexisting behavioural belief and the normative beliefs. The behavioural beliefs produces positive or negative attitudes towards the expected behaviour. The positive attitudes contribute to stimulate a strong intention to perform the behaviour. The normative beliefs are the expectation of others which motivate to comply with the expectations. Greater the expectations of others or social pressures also contribute to stimulate a strong intention to perform the behavior. Accordingly, the strong intention is manifested by the two antecedent beliefs, behavioural belief and the normative belief. The strong intention is the immediate antecedent which finally determines the expected behaviour.

Even-though the theory of reasoned actions was confirmed in many research studies [16], some researches later found out that the strong intention does not always determine the actual behaviour due to circumstantial limitations [13]. Hence, the theory of reasoned behaviour was later expanded by the Theory of Planned Behaviour [3, 4].

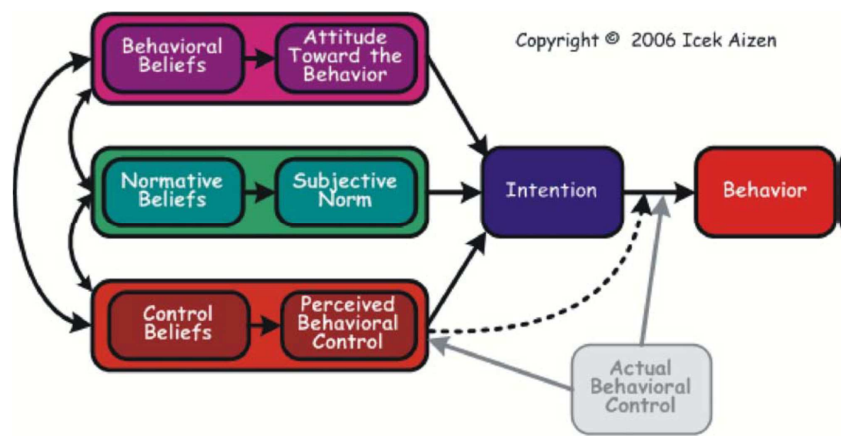

Source: Ajzen (2006).

Figure 1. Theory of planned behaviour.

The theory of planned behaviour (Figure 1) is an extension of the Theory of Reasoned Actions by the inclusion of a new determinant called "Perceived Behavioural Control" which means the perceptions of the person's ability to perform the expected behaviour. The perception is determined by the selfefficacy which means the degree of confidence to perform the expected behaviour. The degree of confidence is determined by the availability of resources and the ability to control the barriers for enacting the behaviour. Hence, according to the Theory of Planned Behaviour, the three antecedents, namely, more positive attitudes, more favourable social norms and more favourable perceived control determine a strong intention to act. Finally the strong intention to act demonstrates the actual behaviour.

\section{Methodology}

This research tests the socio-psychological model called Theory of Planned Behaviour [3] to evaluate the ex-ante and ex-post behavioural aspect of strategic management decision and their implementation of water conservation project.
Even-though the model was introduced and mainly tested on positivist approach, the lens of interpretivist approach is used in this behavioural study. This approach is justified due to the nature of available data [15], interviews, document analysis and observations. The theory is developed by induction. Hence the consistent methodology is the qualitative research methodology that collects the qualitative data and analysed them thematically based on two research strategies, case study and grounded theory. In the process of thematic analysis, themes identified were categorized. These categories transpired into concepts such as behavioural beliefs, normative beliefs and control beliefs (Table 2). The relationship of these concepts were identified with the strong intention of the strategic management's behaviour to implement the water conservation project.

The study was carried out as a cross sectional study. The entire research process including the data collection, analysis and interpretation was carried out ethical manner. With respect to the trustworthiness and integrity of the research, credibility, dependability, transferability, and confirmability [10] were used instead of the internal validity, external validity, reliability and objectivity latter which are more specific to quantitative research due to the difference of the research paradigm, ontology, epistemology, axiology and methodology. In brief, the subjectivity nature of qualitative research and objective nature of quantitative nature.

The data collected from the three sources, interviews, document analysis and observations enabled to answer the ten research questions (Description under discussion below) relating to the behavioural beliefs, normative belief, control beliefs and intention. While interpreting data collected, the credibility of the findings which refer to the confidence which can be placed upon the findings was ensured by on site experience and field notes, triangulation, member checking, peer examination. The dependability which refers to the stability of the findings over time by making sure that the findings are supported by the data collected was ensured by audit trail for cross checking the audit process, member check and peer examination. The transferability, generalizability which refers to the use of the finding in another context is ensured by rich and thick description of the research process. The confirmability which refers to confirmation of the findings by other researches was ensured by the audit trail and the triangulation by corroborating findings with multiple method, multiple sources of data and two investigators in this research.

\section{Discussion}

The Earth surface is covered with water by $70 \%$ out of which $97.2 \%$ is salty water in the oceans. The remaining $2.8 \%$ is fresh water available for human and other beings but most of fresh water is not accessible because they are in the polar icebergs and glaciers and therefore it is only $0.5 \%$, the freshwater in lakes, rivers and aquifers is accessible for human beings more fully depicted in Table 1 [7]. 
Table 1. Total Salt and Fresh Water Supply.

\begin{tabular}{lcll}
\hline Ocean (Salt water) & $\mathbf{9 7 . 2 \%}$ & Icecaps and Glaciers & $\mathbf{0 2 . 3 0 \%}$ \\
\hline Fresh water & $02.8 \%$ & Ground water & $00.40 \%$ \\
& & Surface water & $00.07 \%$ \\
& & Water in Air & $00.03 \%$ \\
Total water on Earth & $100 \%$ & Total Freshwater on Earth & $02.80 \%$ \\
\hline
\end{tabular}

Source: (EPA 1997: 4).

Accordingly, water is a scarce resource in the world. Some countries of the world are semi-arid countries which are the second driest countries after desserts. The semi-arid countries are of two types, hot semi-arid countries and cold semi-arid countries. Botswana is a hot semi-arid water stress country heavily dependent on limited groundwater due to limited surface water. In addition, the global warming makes Botswana more vulnerable in water scarcity which is a key constraint for both hygiene and sanitation and the developmental activities

\subsection{Background}

Hence, the addressing of water shortage in Botswana is imperative. In general, there are two approaches which can be used for water scarcity [19]. One of them is the invention of new sources of water. This approach is a challenge not only because of political, economic and social factors but also in particular by environmental factors in Botswana. The other approach is the way to address the water scarcity is the conservation of water.

The conservation of water is of two types, supply management and demand management. The demand management of water/de-marketing of water is the mostly applicable method for water conservation [17] because the supply management of water by building dams and purifying plants etc. is costlier. This study relates to the conservation of water by demand management. The efficient use of water in industries, agriculture and residential areas will be able to save water for where necessary.

There are many strategies intended by many policy initiatives to change the behaviour of water users in demand management of water [14]. Efficient water rates charged by water utility authorities from the customers, compliance of plumbing standards and use of water technology are a few strategies. This study relates to the water conservation project implemented with water efficient appliances for atomization of the water. In this technology, a specially designed high speed, heavy misty and shooting out nozzle of the faucets (tap) atomizes water coming out of it by breaking into millions of tiny droplets which increase the surface area of the water such as hands, plates, pots etc. enabling to contact almost all water coming out of the tap. In contrast traditionally used faucets release a large volume of water which bounces on the surface and use only a small fraction, say, $2 \%$ of water wasting the balance $98 \%$. This means that the water atomization technology enables to save $98 \%$ of the water. However, the leverage can be changed to $20 \%$ use and $80 \%$ saving by adjusting the nozzles fixed with the faucets. The saving of water is enormous if all consumers behave collectively responsible manner. For example, Water Utilities Corporation in Botswana has a customer base of 355000 customers to whom the corporation has supplied 70 TCM of portable water in 2016 [18].

Accordingly, water atomization technology (or any other strategy) enables to conserve water but the adoption of the technology is primarily a voluntary behaviour of consumers but not mandatorily required by the law in Botswana or even elsewhere in the world. This is because the behaviour reflected by the legal framework which imposes fine and penalties for breach of the compliance is complex and expensive system which requires a large number of regulated authorities such as tribunals for the enforcement of law by persuasion, warning letters, civil penalties, criminal penalties, suspensions of water supply, disconnections of water supply etc. Therefore, a legal framework is advocated under very limited circumstances. For example, the legal framework of Botswana mainly consists four legal instruments, Water Act of 1968, Water Works Act of 1962, Water Utility Corporation Act of 1970 and Boreholes Act of 1956. In addition, there are nine more legislative enactments such as Environmental Impact Assessment Act of 2011, Town and Country Planning Act of 1978 etc.

Hence, the conservation of water is more effective by voluntary behaviour rather than mandatory behaviour imposed by the law [11]. The voluntary behaviour enables to reach the targets with fewer resources and administration. It reduces the compliance burden allowing tailored responses, minimize opposition in the long term, and allow adoption of innovations like the water conservation project under this study. Since innovative technology for water conservation is available in the market but the biggest challenge is the behavioural change for adoption of technology for water conservation [19].

With regard to the voluntary behaviour for water conservation, there are abundant local, regional and international policy tools, institutional framework together directory nature (not mandatory nature of compliance) of elements of legislations adequate in Botswana. They are exhaustively discussed in the Botswana Integrated Water Resources Management \& Water Efficiency (IWRM-WE) Plan [6]. Accordingly, Department of Water Affairs, Department of Geological Survey, Water Utilities Corporation, Department of Waste Management and Pollution Control and seven other institutes represent the institutional framework in Botswana. The policy framework that IWRM-WE identified includes 31 policy documents. Among them, Revised National Policy for Rural Development (2002), Vision 2016 (now 2036), National Conservation Policy, Wetlands Policy and Strategy (2001), Arable land and development Programme (1997), Ecotourism Policy (2002) etc. advocate for voluntary conservation of water.

The regional policy framework takes a very special place for voluntary behaviour of water conservation in Botswana because of limited surface water extracting from four perennial rivers sharing river basins, Okavango, Zambezi, 
Orange-Senqu and Shashe-Limpopo flowing from neighbouring southern African countries. The SADC (South African Development Community) Protocol on Shared Water causes (2001) founded on Helsinki Rules and the United Nations Convention on the Law of the Non-Navigational Uses of International water causes, stipulates that neighbouring countries should use shared water causes with sound environmentally friendly practices and without prejudice to the sovereignty of neighbouring countries and subject to protocols. This agreement is supported with collateral agreements or four river basins, the Permanent Okavango River Basin between Angola, Botswana and Namibia, the Orange-Senqu River Commission between Botswana, Lesotho, Namibia and South Africa, the Limpopo Water Cause Commission between Botswana, Mozambique, South Africa and Zimbabwe and Zambezi Water Cause Commission between Angola, Botswana, Malawi, Mozambique, Namibia, Tanzania, Zambia and Zimbabwe.

The international policy framework relevant to the water management contained in the Sustainability Development Goals 2030 Agenda. On the agenda, there are 17 SDGs and 169 integrated and indivisible targets together with 230+ indicators. Among the SDGs, SDG 06: Clean Water and Sanitation \& $12^{\text {th }}$ Sustainable Development Goals: Responsible Consumption and Production are meant for voluntary conservation of water. One of the targets of SDG 06 stipulates that " 6.4 By 2030, substantially increase wateruse efficiency across all sectors and ensure sustainable withdrawals and supply of freshwater to address water scarcity and substantially reduce the number of people suffering from water scarcity". SDG 12: Sustainable Development Goals: Responsible Consumption and Production for water conservation encourages not mere voluntary behaviour but responsible behaviour which satisfies five principles, honesty, compassion and respect, accountability, fairness and courage.

\subsection{Analysis of Data}

The golden thread woven across the local, regional and international policy framework discussed above is the water conservation by voluntary behaviour of stakeholders rather than mandatorily imposed by the law. In particular, the voluntary behaviour of industrial/business users is important because they as an individual entity enable to save a large quantity of water with environmental, social and economic benefits to all stakeholders including the planet as a stakeholder. The university under this study comes under the industrial/business user of water.

In the presence of water technology to conserve the water with a price in the market, the most important aspect of water conservation is the voluntary behaviour of the university taking a collective decision by the strategic management for adoption of the water technology and the implementation of the water conservation project. Such a decision is complemented by the environmental psychology reflected by the provision of necessity for conservation of energy and water in the strategic plan 2018-2022.
This study tests the underlying psychological process of the behaviour of the university with the theory of planned behaviour (TPB). Even-though the theory of planned behaviour is the individual's intention for performing a given behaviour, once a team has collectively agreed and implemented the decision, it enables to explain the collective psychological process. In other words, once the strategic management has agreed unanimously or by the majority and implemented the water conservation project, the psychological process of the strategic management can be tested with TPB.

The theory of planned behaviour explains that there are three variables, behavioural beliefs, normative beliefs, control beliefs which enable to make a strong intention to perform the act. Such a strong intention results in the expected behaviour. Therefore the four variables, behavioural beliefs, normative beliefs, control beliefs and the intention to act are investigated to substantiate the behaviour reflected by the implementation of the water conservation project.

The first variable, the behavioural beliefs are the beliefs which create positive or negative attitudes towards the behaviour. In this respect, three questions were asked. The first question was what were the advantages of your team identified for the prospective project at that time? The responses disclosed that the continuous flow of water supply during the operation of the university, Saving of water bills, affordable cost of investment, short payback period, easy installation by replacing faucets and other ancillary parts, their experience of similar projects previously implemented elsewhere in Africa, reducing of water footprint by atomization of the water and better future for society and preserve nature, their contribution for Botswana as a water stress country, were disclosed. These responses indicated positive attitudes of the strategic management towards the project. Then the next question was what were the disadvantages identified by you as a team? The response disclosed were that the resistance to change the habit to conserve water atomized in the short term but not in the long term and inconvenience to the users of water during installation. This response indicated creation of negative attitudes. The third question posed was what else you have deliberated other than you have already explained? The answer was that any resistance to change by the students or any other stakeholders can be managed by readjusting the nozzles to increase the water flow. All these responses were corroborated by the observation and the analysis of records maintained for the project. Hence, the strategic management had very positive attitudes to proceed with the prospective water conservation project at that time.

The second variable, the normative beliefs are the beliefs that the given behaviour will be approved or disapproved by the referent group. In this regard, three questions were asked. The first question was asked to list the persons or groups who would approve the expected behaviour? The responses disclosed were that the other universities in Botswana and around the world, regulatory authorities of the university, water utility of Botswana, sustainability loving people, the 
committee appointed for monitoring SDGs in Botswana were considered as referent individuals and groups. The responses above were corroborated with the documents available in the public domain. The second question was asked to list the referent individuals or groups who would not approve the expected behaviour? The answer was that they did not identify any challenges from any referent individual or group for the sustainability practice. The third question was who in your capacity would or would not decides to implement such a project? The answer given was that there was no reason to believe that any university would not consider for such a water conservation project in Botswana in the presence of conducive local, regional and international policy framework for water conservation unless they have priorities. These responses given in these questions demonstrated the motivation created by the social norms to take the decision and implementation of the project.

The third variable, the control beliefs are the beliefs if there are adequate resources and opportunities or not for the given behaviour. In this respect, two questions were asked. The first question was asked to list factors that make the project easy to implement. Bearable increment cost, shorter payback period, easy installation within a short period, fitting into the existing installation by fixing faucets and accessories were the list of factors made the strategic management felt easy to implement the project. These responses were further corroborated by observations and the analysis of documents maintained for the project.

The fourth variable, the intention to act for the given behaviour means that how far they have determined to act for the given behaviour. In this respect, the questions posed was that how much efforts the strategic management strived to act for the planned behaviour? The answer was that all the possible efforts such as consulting experts, personally experience like projects, financial viability, evaluation of resistance to change, the minimization of inconvenience which would take place during the installation and even recording and collection of financial data and non-financial data such as responses of consumers after installation from academic staff, non-academic staff and students were also well planned.

\section{Results \& Findings}

The behavioural beliefs of the strategic management created the positive attitudes of them by the categories disclosed under the column of final category of the Table 2 to have a strong intention for implementing the water conservation project.

The normative beliefs produced the social pressure and influenced the strategic management by the categories disclosed under the column of final category of the Table 2 to have a strong intention for implementing the water conservation project.

The control beliefs produced the perceived control behaviour of the strategic management by the categories disclosed under the column of final category of the Table 2 to have a strong intention for implementing the water conservation project.

The aggregate of three variables, namely, behavioural beliefs which created positive attitudes, normative beliefs which created social norms/social pressure/social influence and control beliefs which created "Perceived Behavioural Control" produced a strong intention to act for the expected behaviour by implementation of the water conservation project. The strong behaviour of the strategic management was corroborated by all the efforts taken by the strategic management for planning, implementation and control functions of the project.

Table 2. The themes and categories generated and their content generated from qualitative research.

\begin{tabular}{|c|c|c|}
\hline Concepts & Categories & Themes \\
\hline \multirow[t]{10}{*}{ Behavioural beliefs } & Positive attitudes for water saving & Continuous flow of water \\
\hline & & Cost saving \\
\hline & & Affordable cost of investment \\
\hline & & Short payback period \\
\hline & & Easy installation \\
\hline & & Previous experience elsewhere \\
\hline & & Reducing water footprint \\
\hline & & Better future for society and preserve nature \\
\hline & & Water stress country \\
\hline & Negative attitudes for the water saving & $\begin{array}{l}\text { Resistance to change the habit to conserve water in the beginning } \\
\text { Inconvenience to the users of the water during installation }\end{array}$ \\
\hline \multirow[t]{3}{*}{ Normative beliefs } & $\begin{array}{l}\text { People who approve the water saving } \\
\text { behaviour }\end{array}$ & Conducive local policy, legal and institutional environment for water conservation \\
\hline & & $\begin{array}{l}\text { Conducive regional policy, legal and institutional environment for water conservation } \\
\text { Conducive global policy, legal and institutional environment for water conservation } \\
\text { Water conservation projects at universities around the world } \\
\text { SDGs: } 06 \text { \& } 12 \text { in particular }\end{array}$ \\
\hline & $\begin{array}{l}\text { People who disapprove the Water saving } \\
\text { behavior }\end{array}$ & Nobody disapproves \\
\hline \multirow[t]{2}{*}{ Control beliefs } & $\begin{array}{l}\text { Factors or circumstances that allow / } \\
\text { Facilitate to save water }\end{array}$ & Fits into the existing installation \\
\hline & & $\begin{array}{l}\text { Easy installation within a short period } \\
\text { Bearable incremental cost }\end{array}$ \\
\hline
\end{tabular}




\begin{tabular}{lll}
\hline Concepts & Categories & Themes \\
\hline & Factors or circumstances that make it & Shorter payback period \\
& Resistance to change in the beginning \\
\hline
\end{tabular}

\section{Conclusion}

Theory of planned behaviour (TPB) which was qualitatively tested the psychological process of the implementation of the water conservation project by the strategic management concluded that the behaviour is a manifestation of four antecedents of the theory of the planned behaviour. Accordingly, the said behaviour was a result of the strong intention, the immediate precedent of the behaviour, to implement the water conservation project by the strategic management. The strong intention to act so is manifested by the aggregation of three beliefs of the strategic management, namely, personal belief, normative belief and the control belief. In other words, the expected behaviour would not have been reflected in the absence of the strong intention to act [8] and the three antecedents of the strong intention which determined the strong intention of the strategic management. Accordingly, the theory of planned behaviour was successfully proved by the water conservation project implemented by the strategic management.

\section{List of Abbreviations}

ASSAR - The Adaptation at Scale in Semi-Arid Region $\mathrm{CO}_{2}$ - Carbon Dioxide

IWRM-WE - Integrated Water Resources Management \& Water Efficiency

SADC - South African Development Community

SDGs - Sustainability Development Goals

TPB - Theory of Planned Behaviour

TRA - Theory of Reasoned Action

\section{Declaration}

\section{Availability of Data and Supporting Materials}

Data sharing not applicable to this article as no dataset were generated or analysed during the current study.

\section{Competing Interests}

The authors declare that they have no competing interest in this study.

\section{Funding}

The contents of this study are solely the opinions of the authors and are not influenced by the funding agencies and no funding for the study was sought and no funding has been received for the study. The authors declare that there are no competing financial or any other interests for the study.

\section{Authors' Contribution}

S. I. H. L. conceived the study and drafted the manuscript. V. V. designed the study and edited the manuscript. Both authors read and approved the final manuscript.

\section{References}

[1] Ajzen, I. \& Fishein, M. (1969). The Prediction of Behavioral Intentions in a Choice Situation. Journal of Experimental Social Psychology, 5, 400-416.

[2] Ajzen, I. \& Fishein, M. (1980). Understanding Attitudes and Predicting Social Behaviour, Prentice-Hall: Englewood Cliffs, NJ.

[3] Ajzen, I. (1991). The Theory of Planned Behaviour. Organizational Behaviour and Human Processes, 50, 179211.

[4] Ajzen, I. (2006). Behavioral Interventions Based on the Theory of Planned Behavior Behavioral Interventions Based on the Theory of Planned Behavior. Available from: file://E:/Users/STZ/Downloads/Behavioral_Interventions_Ba sed_on_the_Theory_of_Pl.pdf [Accessed $20^{\text {th }}$ March, 2020]

[5] CDKN: Climate \& Development Knowledge Network (2018). Opinion: What global warming of $1.5^{\circ} \mathrm{C}$ and higher means for Botswana and Namibia. Available from: https://cdkn.org/2018/10/opinion-what-global-warming-of-15-\%E2\%84\%83-and-higher-means-for-botswana-andnamibia/?loclang=en_gb [Accessed $10^{\text {th }}$ June 2019].

[6] Department of Water Affairs- Ministry of Minerals, Energy \& Water Resources (2013). Botswana Integrated Water Resources Management \& Water Efficiency Plan. (L. Dikobe, Ed.) Gaborone, Botswana: Government of Botswana.

[7] EPA (1997). Water Pollution Prevention and Conservation Pollution Prevention (P2) Education Toolbox Tools for Helping Teachers Integrate P2 Concepts in the Classroom. United States Environmental Protection Agency. EPA-905-F97-011.

[8] Harrison, D. A., Mykytyn, P. P., \& Riemenschneider, C. K. (1997). Executive decisions about adoption of information technology in small businesses: Theory and empirical test. Information Systems Research, 8 (2), 171-195.

[9] Le Quéré, C., Andrew, R. M., Friedlingstein, P., Sitch, S., Hauck, J., Pongratz, J., Pickers, P. A., Korsbakken, J and 69 more (2018) Global Carbon Budget. Earth Syst. Sci. Data. 10, 2141-2194, Available from: https://doi.org/10.5194/essd-102141-2018, 2018 [Accessed 10 ${ }^{\text {th }}$ June 2019].

[10] Lincoln, Y. S. \& Guba, E. G. (1985). Naturalistic Inquiry. Newbury Park, Ca: Sage Publications.

[11] Marandu, E. E., Moeti, N. \& Joseph, H. (2010). Predicting Residential Water Conservation Using the Theory of Reasoned Action, J Communication, 1 (2), 87-100.

[12] Ministry of Minerals, Energy \& Water Resources (2012). Botswana National Water Policy. Available from: https://www.water.gov.bw/images/Water\%20Pitso/Water_Poli 
cy_November_2012.pdf [Accessed $08^{\text {th }}$ June 2019].

[13] Norberg, P. A., Horne, D. R., Horne, D. A. (2007). The privacy paradox: Personal information disclosure intentions versus behaviors. Journal of Consumer Affairs. 41 (1), 100 126. DOI: $10.1111 / \mathrm{j} .1745-6606.2006 .00070$.

[14] Pearce, R., Dessai, S. \& Barr, S. (2013). Re-Framing Environmental Social Science Research for Sustainable Water Management in a Changing Climate. Water Resource Manage. 27: 959. Available from: https://doi.org/10.1007/s11269-0120184-0 [Accessed 19 ${ }^{\text {th }}$ June 2019].

[15] Renzi, R, Jane, E. \& Barr, S. (2008) Using the Theory of Planned Behavior with qualitative research. Working Papers 012, "Carlo F. Dondena" Centre for Research on Social Dynamics (DONDENA), Universita Commerciale Luigi Bocconi.

[16] Sheppard, B. H., Hartwick, J. \& Warshaw, P. R. (1988). The theory of reasoned action: A meta-analysis of past research with recommendations for modifications and future research. Journal of Consumer Research. 15 (3), 325-343. doi: $10.1086 / 209170$.

[17] Steg, L., \& C. Vlek (2009), Encouraging pro - environmental behaviour: An integrative review and research agenda, $J$. Environ. Psychol. 29 (3), 309-317, doi: 10.1016/j.jenvp.2008.10.004.

[18] Water Utilities Corporation (2015/16). Annual Report 2015/16. Available from: https://www.wuc.bw/common_up/wucnew/files/ANNUAL_REPORT_2015-16.pdf [Accessed on 19th June 2019].

[19] Xiong, Y. J., Hao, X. R., Liao, C. \& Zeng, Z. N. (2016). Relationship between water-conservation behavior and water education in Guangzhou, China. Environ Earth Sci. 75: DOI 10.1007/s12665-015-4873-xi. 